\title{
CFD Modelling of Kiwifruit Vines and Leaves: A method of handling multiple thin surfaces
}

\author{
R.J. Connell ${ }^{\text {a }}$, A.M. Endalew ${ }^{\text {b }}$, P. Verboven ${ }^{\text {b }}$ \\ ${ }^{a}$ Lincoln Ventures Ltd, PO Box 133, Christchurch 7640, New Zealand, ${ }^{b}$ Division of Mechatronics, Biostatistics \\ and Sensor, Katholic University of Leuven, Willem de Croylaan 42, Box 2428, 3001 Heverlee, Belgium \\ Email:Robert.Connell@lvl.co.nz
}

\begin{abstract}
Modelling air flow through vegetation is important in many areas of horticulture both for air quality monitoring and for calculating spray drift from agrichemical spraying operations. Modelling vegetation in computational fluid dynamics (CFD) has traditionally been carried out using the porous media properties of the leaves and branches. This entails an extra sink term in the momentum equations for the drag force of the leaves and branches; an extra source term for the turbulent kinetic energy generated by the vegetation; and the corresponding sink term for the turbulent dissipation.
\end{abstract}

More complex models have been developed by Katholic University Leuven that have branching included into the CFD model with the leaves, small branches and petioles modelled using the porous media approach.

The kiwifruit vine model developed here took this one step further to include details of the leaves but omitted the smaller branches and petioles, due to their small scales/sizes. The leaves were generated from the output of a model of a kiwifruit vine developed using the L-system-based plant modelling platform, L-studio. The output was converted into a suitable format for CFD using a conversion program, C4W.

The leaf model developed did not include the leaf edges in the mesh as this would have created cells that were too small to run the model. The ANSYS workbench can include thin-surfaces in the model domain but it was impractical to handle that many leaves. The model was developed using the standard meshing in CFX version 12.1 to create a leaf with no edge. This was done by giving the leaf its normal width of about $200 \mu \mathrm{m}$ and specifying a minimum cell size of $4.5 \mathrm{~mm}$.

The resultant leaf had a surface on either side, with about 35 faces each side to simulate the curved surface of the leaf. The present model was adequate only up to 200 leaves due to the large number of leaf surface boundaries that the CFD model cannot handle at present. Methods to reduce this are currently being investigated.

The resultant CFD model was developed so it did not need sink/source terms for the vegetation and gave the main properties of the kiwifruit vine including the drag from the branches and leaves, as shown by the velocity field in Figure 1. This allows detailed modelling of droplet deposition on to the leaf, consideration of turbulence intensity and the inclusion of a droplet retention/deposition model. The problem of the change in drag created by movements or leaf fluttering is to be the subject of future research. The model will be validated using turbulence and wind data from a series of sonic anemometers sited within and above the plant canopy.

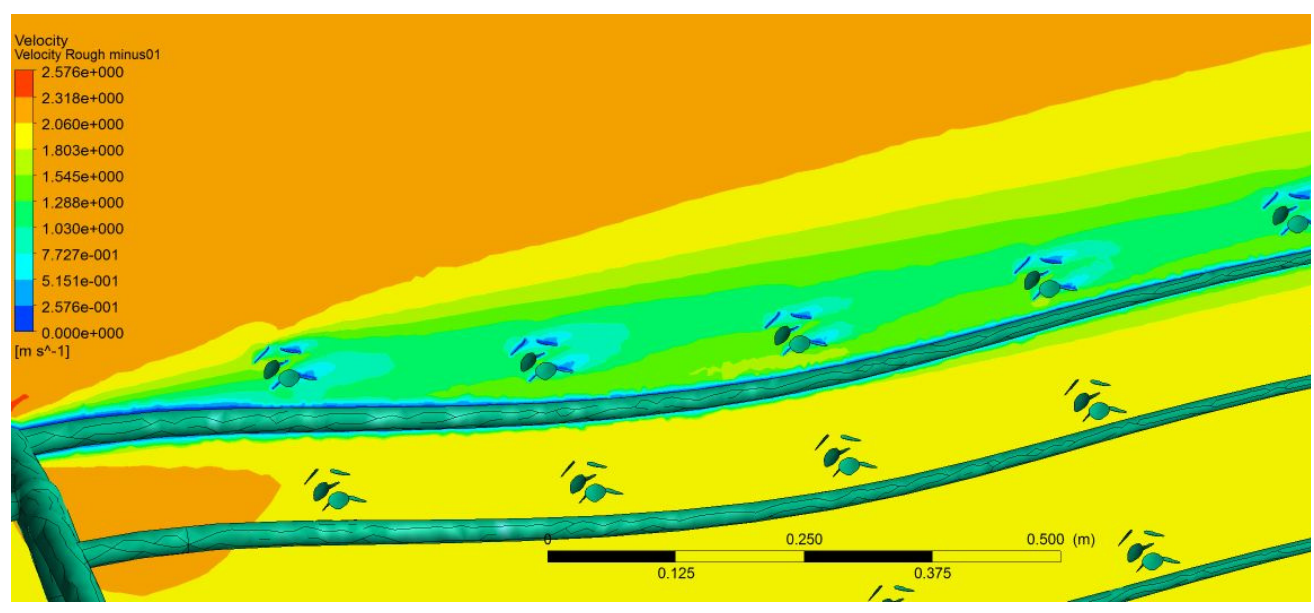

Figure 1: Velocity on a plane along one branch with leaves on a kiwifruit vine.

Keywords: CFD modelling, leaves, thin surfaces, L-systems 


\section{INTRODUCTION}

Agrichemical spraying of orchards accounts for $41 \%$ of the total use of pesticides in New Zealand (Manktelow et al., 2005) with the largest use on kiwifruit (if the spraying of mineral oils on apples is omitted). The pesticide loading of kiwifruit spraying is also the highest, at $24 \mathrm{~kg}$ of active ingredient per hectare per year, so research on the drift from kiwifruit spraying is a high priority for New Zealand.

A CFD model for kiwifruit spraying is, therefore, being developed. This involves a new approach to canopy modelling that includes the actual leaves in the model instead of the usual porous media. The use of the actual leaves in the model will enable more detailed modelling of the droplet paths onto the leaves, taking into consideration the importance of local turbulence intensity (Cole and Corrigan, 2009) and better droplet retention modelling, e.g. examining the effect of the droplet impact angle (Forster, 2010)

One of the objectives of this research programmes is the use of a fast end user model for orchard spraying. A very fast, good end user model is AGDISP (Bilanin et al., 1989) which can run in less than one minute for most cases of aerial spraying of forests, for which it has been built. AGDISP also has ground spraying model, (Teske et al., 2009) which needs more development, but does not have an orchard model.

The aim is to develop an orchard model for AGDISP using the results from field experiments, wind tunnel experiments and a computational fluid dynamics (CFD) model. The rationale for this approach is that field experiments can only be undertaken done for a few sets of weather conditions unless there is unlimited expenditure and time. To simulate the complete range of weather conditions not able to be obtained in the field requires the use of CFD. This means that the CFD model needs to be well calibrated so is can be used for many quasi-field experiments to cover the complete range of field experiments.

AGDISP also needs to include a good description of the turbulent velocity field. The current model uses a very simple but powerful description using friction velocity over open ground, or above, a plant canopy. This is the same model that is used for inputting turbulent kinetic energy for boundary conditions in the RANS (Reynoldsaveraged Navier-Stokes) CFD models (Blocken et al., 2007).

The CFD model will calculate the turbulent velocity field within the canopy, which can then be modelled for AGDISP. The turbulence velocity field of the CFD model will then be validated by sonic anemometer data collected over a range of weather conditions and at positions within and around the plant canopy. Modelling of vegetation in CFD has been carried out using the porous media properties of the leaves and branches, (Maerschalck et al., 2010). This required an extra sink term in the momentum equations for the drag force of the leaves and branches; an extra source term for the generation of the turbulent kinetic energy by the vegetation; and the corresponding sink term for the dissipation of this turbulence by the viscosity of the air which through the turbulence cascade process turns the turbulent kinetic energy into heat.

A more complex CFD model has been developed by (Endalew, 2009) that incorporated the main branches into the CFD model using the porous media approach to model the leaves, small branches and petioles.

The current model of the kiwifruit vine has taken this one step further to include details of the leaves using a plant growth model but omitting the smaller branches and petioles, due to their very small size. Including leaves in the CFD model means it will not need extra terms for the leaves drag force.

\section{CONSTRUCTION OF THE KIWIFRUIT VINEPLANT CANOPY WITH LEAVES}

\subsection{The kiwifruit vine}

The kiwifruit vine has an unusual plant canopy with a very large understory and a thin canopy over the top. The plant is grown on

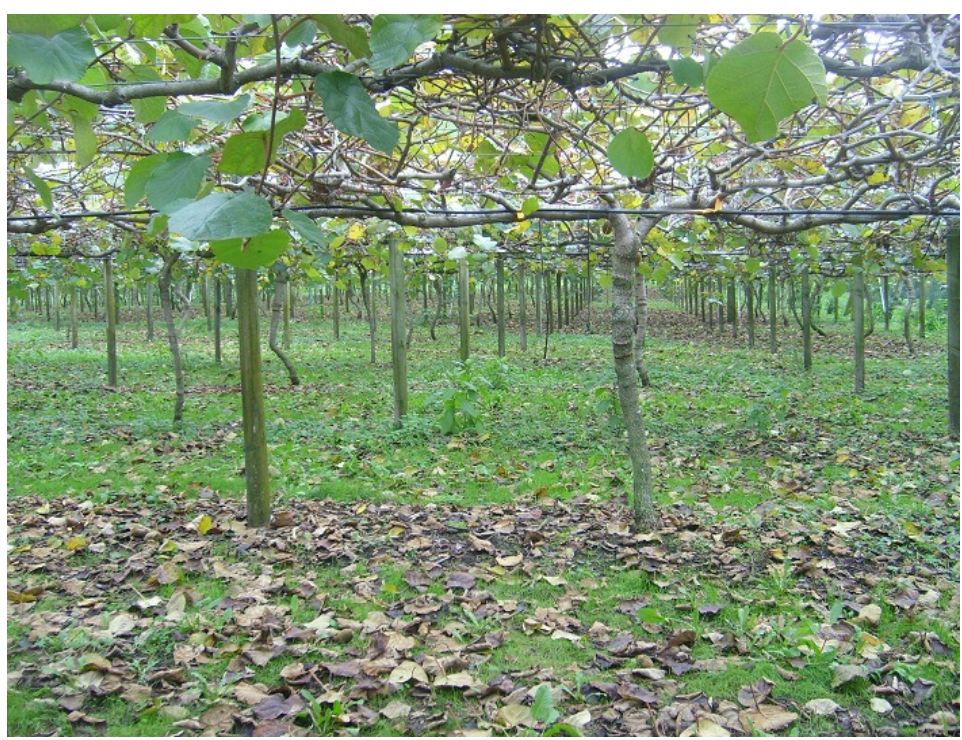

Figure 2. The kiwifruit vine understory and canopy (photo C. Lipscombe). 
support structures that are generally $1.8 \mathrm{~m}$ in height with the plants attached to wires that are tied between the posts of the structure. A view of the understory and vine is shown in Figure 2.

The plant has a trunk, off which two leaders are trained parallel to the ground. Canes come from these leaders, which are generally trained at right angles to the leaders parallel to the ground, as shown in Figure 3 . Stems grow upwards off these canes with the leaves connected by a small branch, called a petiole, as shown in Figure 4.

\subsection{Vine model with leaves}

To obtain a better model of the turbulent velocity field, a detailed model of the plant and its structure, including the leaves, needed to be imported into the CFD model. The detail required was taken from a plant growth model. For the kiwifruit vine the detailed model was from an L-systems based model called L-studio (The virtual Laboratory, 2011). A model of a kiwifruit vine was previously developed at the University of Queensland, (Cieslak et al., 2009) and the L-studio model of this structure is shown in Figure 4.

The kiwifruit vine model export file from L-studio (.obj format) was converted to .stp format using $\mathrm{C} 4 \mathrm{~W}$ (C4W, 2011).

There were, however, issues with the L-studio model in the ANSYS platform, as each branch was hollow, open ended and divided into different parts. This approach dictated that the branches and trunk needed to be constructed using their centre lines. The resulting plant model was converted to the CFD format, using a routine developed by (Endalew 2009), to ensure that the plant model could be exported into CFX (ANSYS, 2011). Further work has shown that a better L-studio model could be converted by C4W straight into CFX designmodeler. This would entail using generalised cylinders for the trunk and branches and placing caps on the end of the cylinders to close them (Měch et al., 2010) so they can then be turned into solids using C4W.

The wooden posts that supported the canopy were added to the model but the wiring holding the plant was

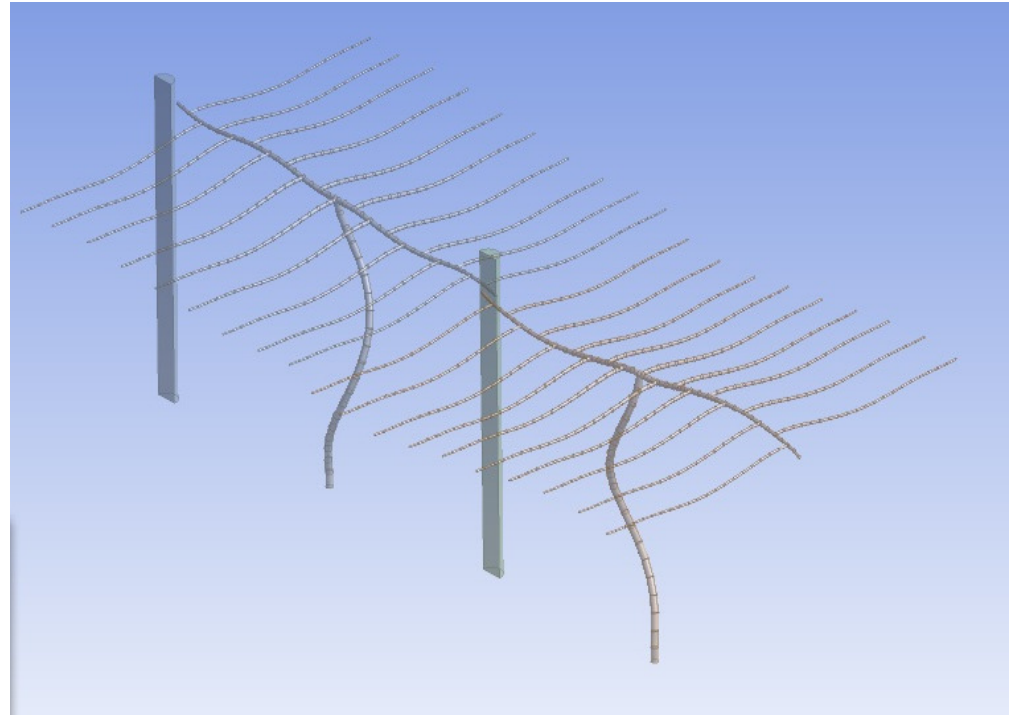

Figure 3. Model of the kiwifruit vines (no leaves) in designmodeler.

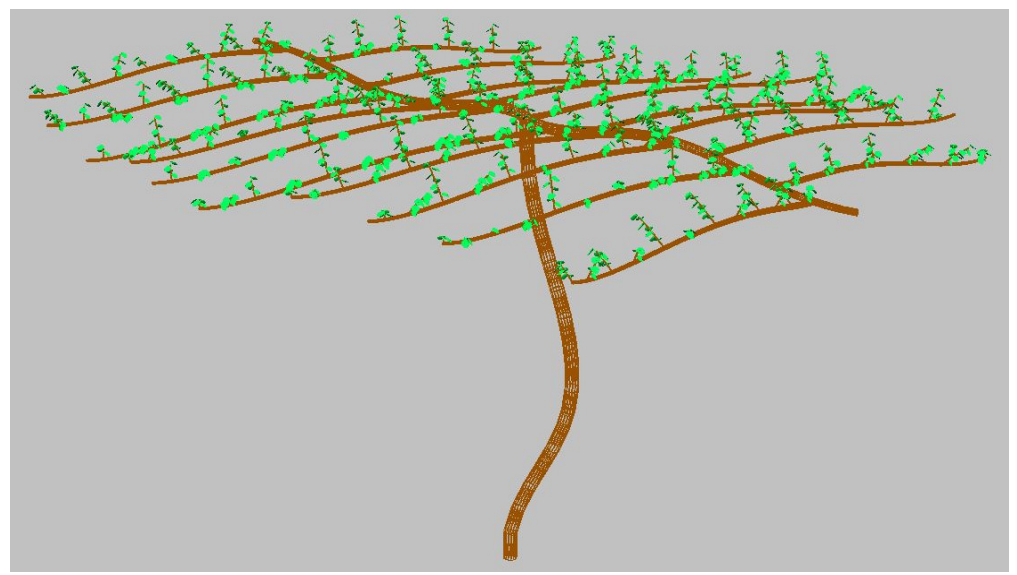

Figure 4. The L-studio model of the kiwifruit vines showing a small amount of leaf growth. not. This was because including the wiring would make the mesh too small for the CFD model to run in a realistic time. It was decided to model two vines as this would allow for interactions with the post in between the vines, as shown in Figure 3 .

\subsection{Leaf edge issue}

The problem with the development of a model that included the leaf edges in the mesh is that it would create cells that were too small, resulting in too many cells and too small a time step for the solution to run within a 
realistic time frame. There are about 1,000 leaves on the L-studio model of the kiwifruit vine but each has only a small amount of growth, as shown in Figure 4.

The ANSYS workbench can include thin-surfaces in the model domain but it was impractical to handle the more than 1,000 such surfaces the leaves would require. The model was developed using standard meshing in the ANSYS CFX platform creating a leaf with no edges. This was undertaken by giving the leaf its normal width of about $200 \mu \mathrm{m}$ and specifying a minimum cell size of $4.5 \mathrm{~mm}$. The resultant leaf had a surface on either side, with about 35 faces on each side to simulate the curved surface of the leaf.

This method was also carried out using ICEM meshing in the ANSYS suite of programs but with a larger (500 micron) width of leaf.

Figure 5 shows a cross-section through the leaves and the mesh and shows how the leaf width is much smaller than the mesh size. Figure 6 shows the set of leaves that occur with a small amount of growth from the cane.

As the branches and canes did not exactly line up with the L-studio model (due to the different method used to build them) a set of leaves, as shown in Figure 6, was copied and placed over the canes at the correct points.

The present model could only have 186 leaves due to the large numbers of boundaries from the leaf surfaces that the CFD model cannot handle at present. This meant that only one plant could be modelled that contained leaves for four branches. The model takes several minutes just to load 186 leaves. Methods to reduce this time are currently being investigated.

The model of the vine with leaves, constructed with the workbench mesher contained about 3.5 million cells. This was well over that using ICEM meshing, which had as many cells for the two vine model (the leaves added about $20 \%$ to the number of cells for the vine with no leaves).

\section{COMPUTATIONAL SETUP}

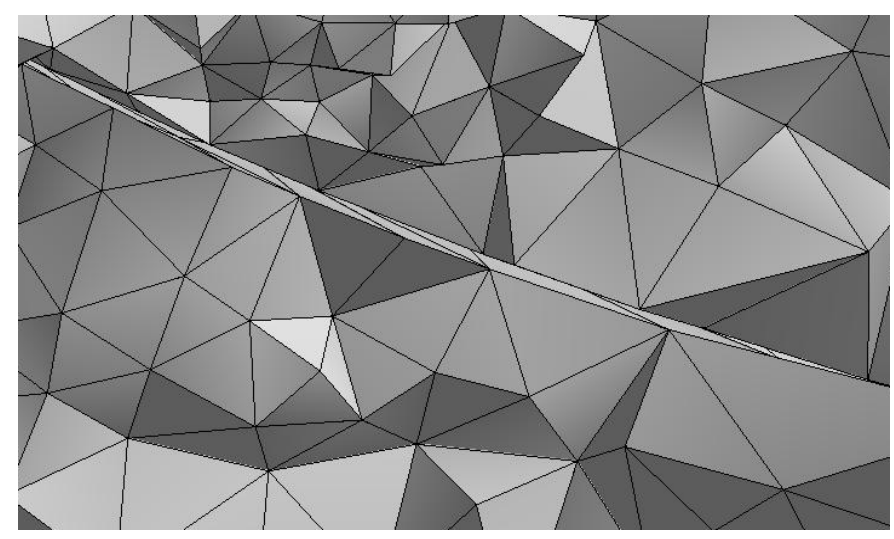

Figure 5. A cross-section through the leaf and mesh showing the thickness of the leaves within the mesh.

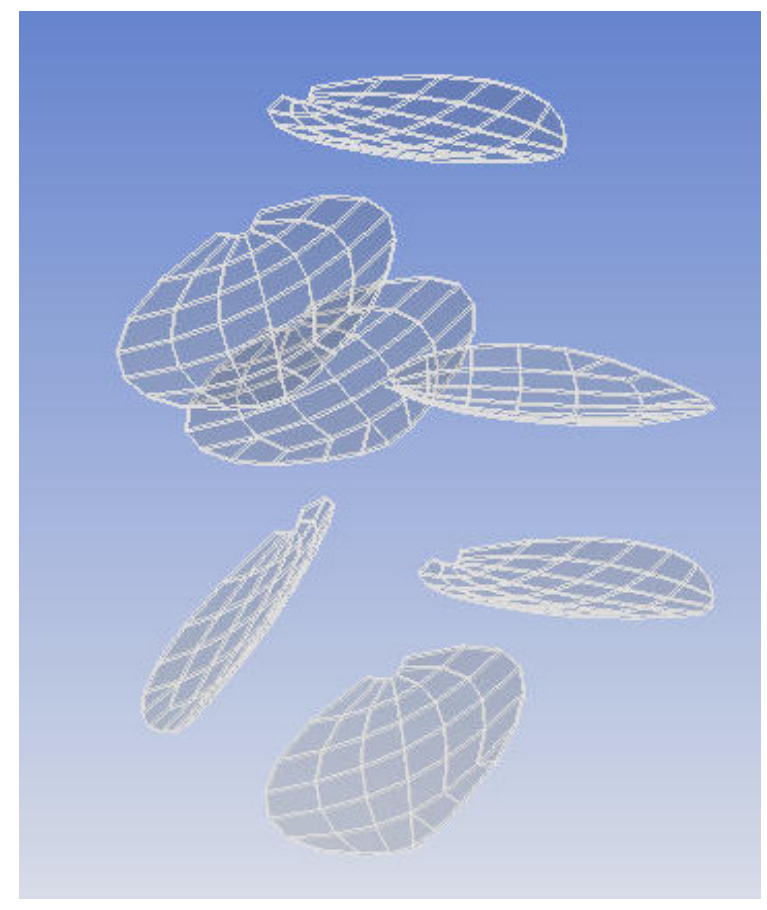

Figure 6. A typical set of leaves from a small branch arising from the leaders. Note that the small branches that lead from the canes and leaf petioles are not present.

\subsection{Domain size}

The domain model size was $6 \mathrm{~m}$ high (just over three times the height of the canopy) and $6 \mathrm{~m}$ wide and $3.3 \mathrm{~m}$ deep (in the direction of wind flow). The domain was kept to this size based on previous modelling experience and was a suitable unit size within the kiwifruit vine field, which consisted of hundreds of such vines. Spray drift downwind could easily be modelled using this unit by inputting the downwind boundary results into the upwind boundary of the next downwind unit and so on. 


\subsection{Numerical Scheme and Boundary conditions}

The model was run on CFX using the shear stress transport (SST) scheme, a Reynolds Averaged Navier-Stokes (RANS) type model, as this scheme handles flow separation well. This model uses the k- $\varepsilon$ model for the outer region of the boundary layer and the k- $\omega$ model for the inner boundary layer (Davidson, 2011; Menter, 1994).

To ensure that the energy of the wind was not lost due to the resistance provided by the trees and ground, the boundary condition at the top of the model was changed to a wind velocity equal to the log law value at $6 \mathrm{~m}$ above the canopy; this velocity would be quite close to the expected value. (This will be subsequently reviewed due to the $2 \mathrm{~m}$ height of the kiwifruit vine canopy). This energy is needed on the top boundary, as the whole of the boundary layer, which is 1 to $2 \mathrm{~km}$ in height, is driven by the regional atmospheric conditions, e.g. a high or low pressure system from a local sea breeze, which provided the overall energy for the wind flow in the orchard.

The standard k- $\varepsilon$ values for turbulent kinetic energy (TKE) and turbulent dissipation (TD) were also added to both the inflow boundary condition and the top boundary. These values were not be exactly correct for the SST model on the inlet boundary near the ground, where it was assumed to be grass with a sand roughness of $0.01 \mathrm{~m}$. However, the next step, as discussed below, is to model just one branch and leaves, where the SST model will calculate the TKE and TD, which will then be calibrated with field data will overcome this problem.

The model also used symmetrical boundary conditions on the side boundaries. As the wooden posts were close to the side boundaries, and would be reflected in the boundary, the model could be improved by shifting the boundary to the mid-point of the wooden posts. Since this was not done there will be small effects from having too many posts if the model is seen as part of the complete kiwifruit vine field.

\section{RESULTS}

The results of the simulation are shown in Figure 1 and Figures 7 to 10. The figures show the effect of the leaves reducing the velocity. Examination of the TKE plot (Figure 9) shows that it reduces in the lee of the leaves and drops off downwind along the branch. This has been observed previously in canopies (Walklate, 1993).

The effects from the stem and petioles not included as it is thought that their effect will not be greatly significant but this effect will be assessed by further detailed modelling of a group of leaves, as shown in Figure 5.

The $\mathrm{y}^{+}$values varied from 10 to 60 on the leaves and were over 200 on the stem and wooden posts. The SST scheme can handle this range of $\mathrm{y}^{+}$values, as it has a blending function which gradually changes the wall function from a standard k- $\varepsilon$ function to the low Re near wall

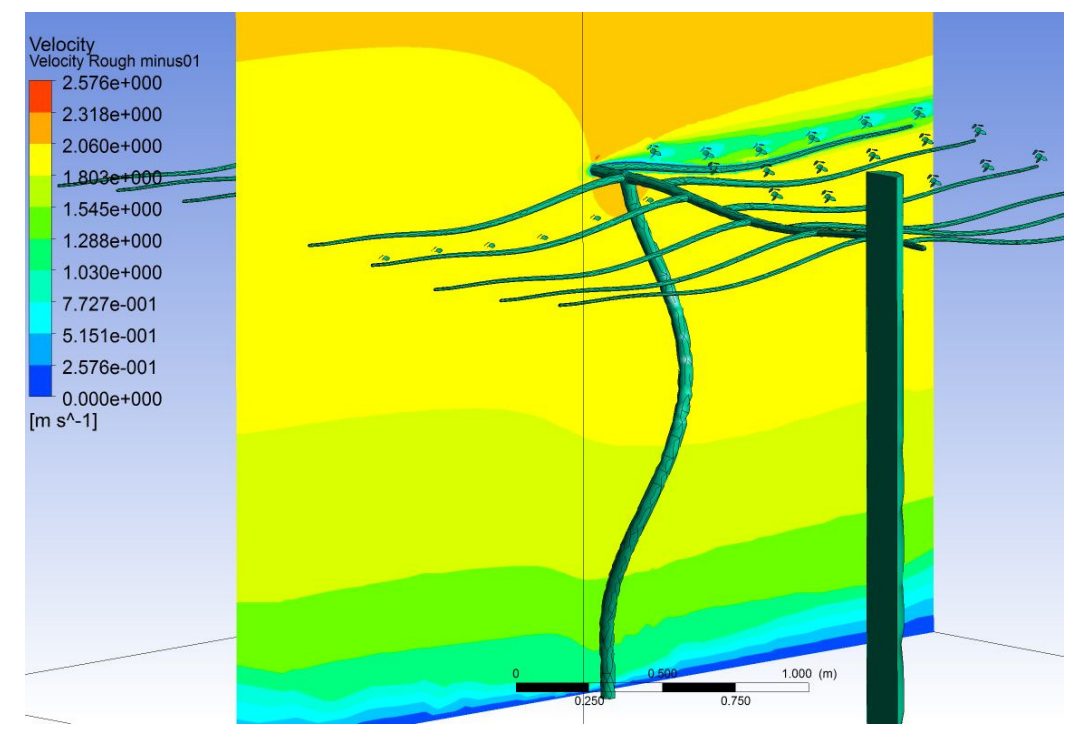

Figure 7. Full view of a velocity on a plane though a branch with leaves. See Figure 1 for velocity detail.

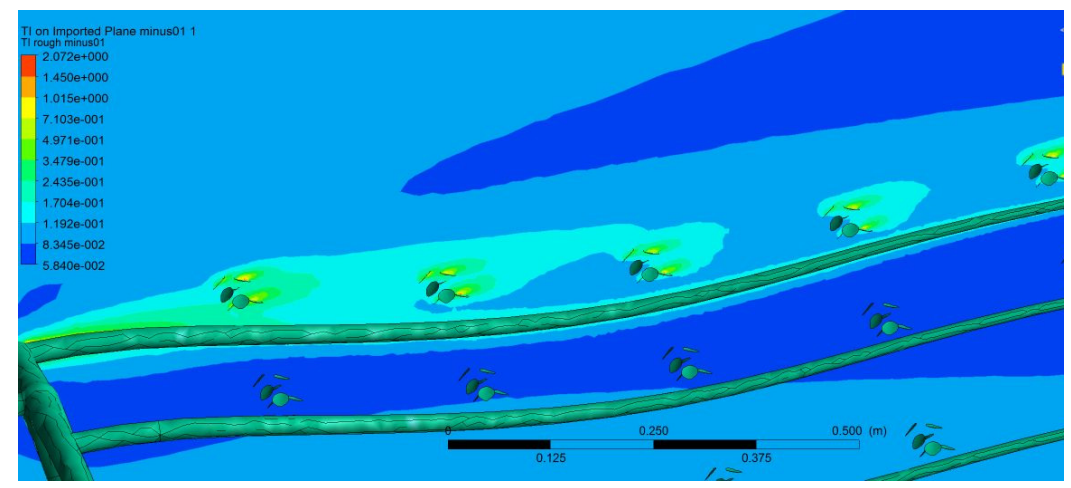

Figure 8. Detailed view of a turbulence intensity on a plane though a branch with leaves 
formulation when $\mathrm{y}^{+}$ changes from 30 to 2 .

\section{CALIBRATION}

A great deal of further work is required to calibrate the model. This will initially be carried out using the velocity and turbulence parameters, turbulence kinetic energy (and/or turbulence intensity) and turbulence dissipation and

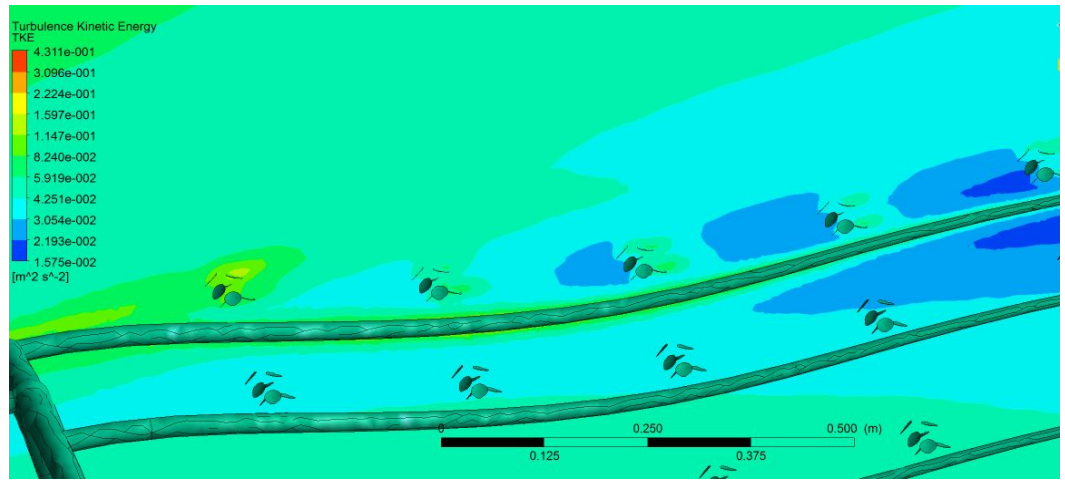

Figure 9. Detail view of a turbulence kinetic energy on a plane though a branch with leaves generation. Other factors, such as the longitudinal turbulence length and turbulence structures, will also be investigated. This will ascertain the ability of the RANS model used and also assess the value of Large Eddy Simulation (LES) or Detached Eddy Simulation (DES).

To calibrate the model field data will be acquired from sonic anemometers to obtain a description of the velocity and turbulence fields throughout the model domain. Several sets of data for a two week period will be obtained using three anemometers set above and within the canopy. The turbulence characteristics of the kiwifruit canopy will be unusual due to its large understory and thin canopy. Reported canopy turbulence intensities are between 0.4 and 1.6, (Wilson et al., 1977) (Cescatti et al., 2004) and (Green et al., 1995). In the last reference, it was reported that the canopy turbulence was dominated by large scale intermittent events.

Some work has been done to assess the turbulence properties of the SST scheme using an open field where it would be expected that the turbulence intensity would be close to that predicted by standard atmospheric turbulence parameters. Near the ground the turbulence intensity $\sigma_{\mathrm{u}} \approx 2.5 \mathrm{u}_{*}, \sigma_{\mathrm{u}} \approx 2.2 \mathrm{u}_{*}, \sigma_{\mathrm{z}} \approx 1.37 \mathrm{u} *$ where $\mathrm{u}_{*}$ is the friction velocity which means, using the standard log law profile, the turbulence intensity, $\mathrm{I}_{\mathrm{u}}$, becomes,

$$
\mathrm{I}_{\mathrm{u}}=\frac{\sigma}{\overline{\mathrm{U}}}=\frac{\sqrt{\frac{1}{3}\left(2.5^{2}+2.2^{2}+1.37^{2}\right)} \mathrm{u}_{*}}{\left(\mathrm{u}_{*} / 0.4\right) \log _{\mathrm{e}}\left(\mathrm{z} / \mathrm{z}_{0}\right)}=\frac{0.83}{\log _{\mathrm{e}}\left(\mathrm{z} / \mathrm{z}_{0}\right)}
$$

Using a ground roughness of $0.01 \mathrm{~m}$, this formula gave turbulence intensities of $16 \%$ at $2 \mathrm{~m}, 13 \%$ at $5 \mathrm{~m}$ and $12 \%$ at $10 \mathrm{~m}$. At $100 \mathrm{~m}$ it drops to $9 \%$. The open field model using the SST scheme gave turbulence intensities of $12 \%$ at $2 \mathrm{~m}, 10 \%$ at $5 \mathrm{~m}, 9 \%$ at $10 \mathrm{~m}$ and $7 \%$ at $100 \mathrm{~m}$. These are below the standard values and further investigation is necessary, by calibrating the model using sonic anemometer data, to obtain the correct intensities otherwise the spray drift predicted by the model will be incorrect as the turbulence intensity is one of the main factors affecting spray drift. The upward motion part of the turbulence intensity carries some particles upwards, where the air turbulence, using the same process, carries some of those particles higher still.

The drag of the branches within a canopy varies with turbulence intensity, (Ko et al., 1972; Bache, 1986). This also needs investigation before a good model of the kiwifruit vine is available.

With the difficulty in inserting large numbers of leaves, it has been concluded that a single branch should be modelled. This will be ideal to model and will form a good basis for a field trial to calibrate the turbulence intensity within the branch together with a droplet retention model; the latter is also being developed as part of the research programme to assess the effect of the angle of approach on droplet retention.

\section{CONCLUSIONS}

A CFD model using ANSYS - CFX has been developed using the plant growth model L-studio with the conversion program $\mathrm{C} 4 \mathrm{~W}$. There were weaknesses in the L-studio model that can be overcome with a better model that would enable $\mathrm{C} 4 \mathrm{~W}$ to do a conversion so it could be loaded straight into the designmodeler of CFX.

Field data from sonic anemometers is required to validate the model using the velocities and turbulence properties of the air flow through, and around, the canopy. A model of a single branch with leaves will enable detailed modelling and assessment of the canopy turbulence and also undertake detailed modelling and calibration of the pesticide deposition on the branch. 
The long term goal of the CFD model is to use it to undertake further quasi-field trials for the development of a fast end-user model for spray managers, which in this case will be on the AGDISP platform. To enable the CFD model to do quasi-field trials a very good calibration over a range of field conditions is necessary that has an emphasis on the velocity and turbulence parameters of the wind flow.

\section{ACKNOWLEDGEMENTS}

The authors would like to thank Harold Thistle and Janette Busch for reviewing this manuscript. This work is done under the FRST contract "Protecting New Zealand's Environment from Pesticide Exposure".

\section{REFERENCES}

ANSYS, (2011). http://www.ansys.com/Products/Simulation+Technology/Fluid+Dynamics/ANSYS+CFX. accessed 2011, ANSYS, Inc., Canonsburg, PA, USA.

Bache, D. H. (1986). Momentum Transfer to Plant Canopies: Influence of Structure and Variable Drag. Atmosphere Environment, 20(7), 1369-1378.

Blocken, B., Stathopoulos, T., Carmeliet, J., (2007). CFD simulation of the atmospheric boundary layer: wall function problems. Atmosphere Environment, 41, 238-252.

Bilanin, A. J., Teske, M. E., Barry, J. W. and Ekblad, R. B. (1989). AGDISP: The Aircraft Spray Dispersion

Model, Code Development and Experimental Validation. American Society of Agricultural Engineers, 32(1), 327-334.

C4W, (2011). http://c4w.fr/ accessed 2011, 219 rue Titian, 34000 Montpellier, France.

Cescatti, A and Marcolla, B. (2004). Drag coefficient and turbulence intensity in conifer canopies. Agricultural and Forest Meteorology 121, 197-206.

Cieslak, M., Seleznyova, A. N. and Hanan, J. (2009). A functional-structural kiwifruit vine model. Third International Symposium on Plant Growth Modelling Simulation, Visualization and Applications. Plant Growth Modelling and Applications 2009, Beijing, China, 9-13 November, 2009, p 206 - 213.

Cole, I.S. and Corrigan, P.A., (2009). Development of a range of methods for estimating the service life of buildings and engineered structures. $18^{\text {th }}$ World IMACS / MODSIM Congress, Cairns, Australia 13-17 July 2009, p310-316.

Davidson, L. (2011). Fluid mechanics, turbulent flow and turbulence modelling. downloaded from world wide web, 2011, http://www.tfd.chalmers.se/ lada/postscript_files/solids-and-fluids_turbulent-flow_turbulencemodelling.pdf

Endalew, A.M., (2009). Computational fluid dynamics modelling of air and particle flow and deposition on canopy structures. PhD Thesis, Katholic Universiteit Leuven, Leuven, Belgium, 195 pp.

Forster, W.A., Mercer, G.N. and Schou, W.C. (2010). Process-driven models for spray droplet shatter, adhesion or bounce. $9^{\text {th }}$ International Symposium on Adjuvants for Agrochemicals, Freising-Weihenstephan, Germany, 1620 August 2010.

Green, S. R., Grace, J. and Hutchings, N. J. (1995). Observations of turbulent air flow in three stands of widely spaced Sitka spruce. Agricultural and Forest Meteorology, 74, 205-225.

Ko, S. C. and Graf, W. H. (1972). Drag coefficient of cylinders in turbulent flow. Proc. American Society of Civil Engineering, 98(HY5), 897-912.

Maerschalck, B. D., Maiheu, B., Janssen, S. and Vankerkom, J. (2010). CFD-modelling of complex plantatmosphere interactions: Direct and indirect effects on local turbulence. CLIMAQS Workshop 'Local Air Quality and its Interactions with Vegetation' January 21-22, 2010, Antwerp, Belgium.

Měch, R., Prusinkiewicz, P and Hanan, J. (2010). Extensions to the graphical interpretation of L-systems based on turtle geometry. Department of Computer Science University of Calgary, Downloaded from Worldwide web, June 2010 from algorithmicbotany.org/lstudio/graph.pdf.

Manktelow, D., Stevens, P., Walker, J., Gurnsey, S., Park, N. and Zabkiewicz, J., (2005). Trends in Pesticide Use in New Zealand: 2004: Report to the Ministry for the Environment.

Menter, F. R. (1994). 'Two-Equation Eddy-Viscosity Turbulence Models for Engineering Applications.' AIAA Journal, Vol. 32, No. 8, August 1994, pp. 1598-1605.

Teske, M. E., Miller, P. C. H., Thistle, H. W. and Birchfield, N. B. (2009). Initial development and validation of the mechanistic spray drift model for ground boom sprayers. Transactions of the ASABE, 52(4), 1089-1097

The Virtual Laboratory (2011). L-studio. http://algorithmicbotany.org/lstudio/ Accessed 2011.

Walklate, P., (1993). The effect of orchard crop structure on the integral scale of turbulence. Boundary-Layer Meteorology 63, 1-22.

Wilson, N., Robert and Shaw, R. H. (1977). A Higher Order Closure Model for Canopy Flow. Journal of Applied Meteorology, 16, 1197-1205. 